\title{
A Damage Model for the Simulation of Delamination in Advanced Composites under Variable-Mode Loading
}

\author{
A. Turon ${ }^{\text {a }}$, P.P. Camanho ${ }^{\text {b,* }}$, J. Costa $^{\text {a }}$, C.G. Dávila ${ }^{\mathrm{c}}$ \\ ${ }^{a}$ AMADE, Polytechnic School, University of Girona, Campus Montilivi s/n, 17071 \\ Girona, Spain \\ ${ }^{\mathrm{b}}$ DEMEGI, Faculdade de Engenharia, Universidade do Porto, Rua Dr. Roberto \\ Frias, 4200-465, Porto, Portugal \\ ${ }^{\mathrm{c}}$ NASA Langley Research Center, Hampton, Virginia, U.S.A.
}

\begin{abstract}
A thermodynamically consistent damage model is proposed for the simulation of progressive delamination in composite materials under variable-mode ratio. The model is formulated in the context of Damage Mechanics. A novel constitutive equation is developed to model the initiation and propagation of delamination. A delamination initiation criterion is proposed to assure that the formulation can account for changes in the loading mode in a thermodynamically consistent way. The formulation accounts for crack closure effects to avoid interfacial penetration of two adjacent layers after complete decohesion. The model is implemented in a finite element formulation, and the numerical predictions are compared with experimental results obtained in both composite test specimens and structural components.
\end{abstract}

Key words: Delamination, Fracture, Decohesion elements 


\section{Introduction}

Structural collapse in a composite structure is caused by the evolution of different types of damage mechanisms, such as matrix transverse cracking, fibre fracture and delamination. The particular damage modes depend upon loading, geometry, lay-up and stacking sequence.

Delamination is one of the most common types of damage in laminated fibrereinforced composites due to their relatively weak interlaminar strengths. Delamination may arise under various circumstances, such as in the case of transverse concentrated loads caused by low velocity impacts. This damage mode is particularly important for the structural integrity of composite structures because it is difficult to detect during inspection. Furthermore, delamination causes a drastic reduction of the bending stiffness of a composite structure and, when compressive loads are present, promotes local buckling.

When other material non-linearities can be neglected, methods based on Linear Elastic Fracture Mechanics (LEFM) have been proven to be effective in predicting delamination growth. However, LEFM cannot be applied without an initial crack. In some situations, methods combining a stress analysis with a characteristic distance have been applied to predict the initiation of delamination [1]-[2]. After delamination onset, LEFM can be used to predict delamination growth [3]-[4]. Techniques such as virtual crack closure technique (VCCT) [5]-[9], J-integral method [10], virtual crack extension [11] and stiffness derivative [12] have often been used to predict delamination growth. These techniques are used to calculate the components of the energy release

\footnotetext{
* Corresponding author

Email address: pcamanho@fe.up.pt (P.P. Camanho).
} 
rate. Delamination growth is predicted when a combination of the components of the energy release rate is equal to, or greater than, a critical value [13].

However, difficulties are also encountered when these techniques are implemented using finite element codes. The calculation of fracture parameters, e.g. stress intensity factors or energy release rates, requires nodal variable and topological information from the nodes ahead and behind the crack front. Such calculations can be done with some effort for a stationary crack, but can be extremely difficult when progressive crack propagation is involved.

Another approach to the numerical simulation of the delamination can be developed within the framework of Damage Mechanics. Models formulated using Damage Mechanics are based on the concept of the cohesive crack model: a cohesive damage zone or softening plasticity is developed near the crack front. The origin of the cohesive crack model goes back to Dugdale [14] who introduced the concept that stresses in the material are limited by the yield stress and that a thin plastic is generated in front of the notch. Barenblatt [15] introduced cohesive forces on a molecular scale in order to solve the problem of equilibrium in elastic bodies with cracks. Hillerborg et al. [16] proposed a model similar to the Barenblatt model, but where the concept of tensile strength was introduced. Hillerborg's model allowed for existing cracks to grow and, even more importantly, also allowed for the initiation of new cracks.

Cohesive damage zone models relate tractions to displacement jumps at an interface where a crack may occur. Damage initiation is related to the interfacial strength, i.e., the maximum traction on the traction-displacement jump relation. When the area under the traction-displacement jump relation is equal to the fracture toughness, the traction is reduced to zero and new crack 
surfaces are formed. The advantages of cohesive zone models are their simplicity and the unification of crack initiation and growth within one model. Moreover, cohesive zone formulations can also be easily implemented in finite element codes using decohesion elements [17]-[25]. Although the cohesive damage models cannot be considered non-local damage models [26], they allow a mesh-independent representation of material softening, provided that the mesh is sufficiently refined.

In the formulation of the cohesive models, it is important to control the energy dissipation during delamination growth in order to avoid the restoration of the cohesive state, i.e., it is necessary to assure that the model satisfies the Clausius-Duhem inequality. There are some models in the literature that can be used under constant mixed-mode conditions [21],[23]-[24], [30]-[35]. However, the models proposed generally do not satisfy the Clausius-Duhem inequality under variable-mode loading situation. Most of the models cited above define the damage threshold parameter as the maximum displacement. This assumption may lead to the violation of the Clausius-Duhem inequality when the crack grows in a varying mode.

The restoration of the cohesive state is illustrated in Figure 1. This Figure represents the traction $(\tau)$-relative displacement $(\Delta)$ relation for two different mode ratios, $G_{I I} /\left(G_{I I}+G_{I}\right)=A($ Figure 1 a $\left.)\right)$ and $G_{I I} /\left(G_{I I}+G_{I}\right)=B$ (Figure $1 \mathrm{~b})$ ), where $G_{I}$ and $G_{I I}$ are the components of the energy release rate. If the mode ratio changes from A to B during delamination growth, there is a restoration of the cohesive state. This effect is clearly inconsistent with the thermodynamical principles.

[Figure 1 about here] 
A damage model for the simulation of delamination under variable-mode is presented in this paper. A new delamination initiation criterion is proposed. The delamination onset criterion stems from the expression of the critical energy release rate for delamination propagation under mixed-mode loading proposed by Benzeggagh and Kenane [36]. The model is implemented in the implicit finite element code ABAQUS [54] by means of a user-written decohesion element.

This paper is structured as follows: first, the formulation of the damage model for the simulation of delamination onset and growth model is presented. The finite element discretization of the boundary value is described. Finally, the numerical predictions are compared with experimental results obtained in composite test specimens and composite structural components.

\section{Model for delamination onset and propagation}

The boundary value problem, the kinematic equations, and the constitutive relations are presented for the formulation of the model for delamination onset and delamination propagation.

\subsection{Boundary value problem}

Consider a domain $\Omega$, as shown in Figure 2(a), containing a crack $\Gamma_{c}$. The part of the crack on which a cohesive law is active is denoted by $\Gamma_{c o h}$ and is called the fracture process zone (FPZ).

[Figure 2 about here] 
Prescribed tractions, $t_{i}$, are imposed on the boundary $\Gamma_{F}$, whereas prescribed displacements are imposed on $\Gamma_{u}$. The stress field inside the domain, $\sigma_{i j}$, is related to the external loading and the closing tractions $\tau_{j}^{+}, \tau_{j}^{-}$in the cohesive zone through the equilibrium equations:

$$
\begin{gathered}
\sigma_{i j, j}=0 \text { in } \Omega \\
\sigma_{i j} n_{j}=t_{i} \text { on } \Gamma_{F} \\
\sigma_{i j} n_{j}^{+}=\tau_{i}^{+}=-\tau_{i}^{-}=\sigma_{i j} n_{j}^{-} \text {on } \Gamma_{c o h}
\end{gathered}
$$

\subsection{Kinematics of the interfacial surface}

To develop the necessary kinematic relationships, consider the crack $\Gamma_{c}$ shown in Figure 2(a) as part of a material discontinuity, $\Gamma_{d}$, which divides the domain $\Omega$ into two parts, $\Omega_{+}$and $\Omega_{-}$(Figure $2(\mathrm{~b})$ ).

The displacement jump across the material discontinuity $\Gamma_{d}, \llbracket u_{i} \rrbracket$, can be written as:

$$
\llbracket u_{i} \rrbracket=u_{i}^{+}-u_{i}^{-}
$$

where $u_{i}^{ \pm}$denotes the displacement of the points on the surface of the material discontinuity $\Gamma_{d}$ of the parts $\Omega_{ \pm}$of the domain.

The fundamental problem introduced by the interfacial surface $\Gamma_{d}$ is how to express the virtual displacement jumps associated to the surfaces $\Gamma_{d^{ \pm}}$as a function of the virtual displacements. Consider a three-dimensional space with Cartesian coordinates $X_{i}, i=1,2,3$. Let the Cartesian coordinates $x_{i}^{ \pm}$describe the position of the upper and lower surfaces $\Gamma_{d^{ \pm}}$in the deformed configuration. Any material point on $\Gamma_{d^{ \pm}}$in the deformed configuration is related 
to its undeformed configuration through:

$$
x_{i}^{ \pm}=X_{i}+u_{i}^{ \pm}
$$

where $u_{i}^{ \pm}$are the displacements with respect to the fixed Cartesian coordinate system. The coordinates $\bar{x}_{i}$ of the midsurface can be written as [37]:

$$
\bar{x}_{i}=X_{i}+\frac{1}{2}\left(u_{i}^{+}+u_{i}^{-}\right)
$$

[Figure 3 about here]

The components of the displacement jump vector are evaluated at the midsurface $\bar{\Gamma}_{d}$, which is coincident with $\Gamma_{d}$ in the undeformed configuration (see Figure 3). The midsurface coordinate gradients define the components of the two vectors, $v_{\eta_{i}}$ and $v_{\xi_{i}}$, that define the tangential plane at a given point, $\bar{P}$ :

$$
\begin{aligned}
& v_{\eta_{i}}=\bar{x}_{i, \eta} \\
& v_{\xi_{i}}=\bar{x}_{i, \xi}
\end{aligned}
$$

where $\eta, \xi$ are curvilinear coordinates on the surface $\bar{\Gamma}_{d}$. Although $v_{\eta_{i}}$ and $v_{\xi_{i}}$ are generally not orthogonal to each other, their vector product defines a surface normal. Therefore, the local normal coordinate vector is obtained as:

$$
\mathbf{v}_{n}=\mathbf{v}_{\xi} \times \mathbf{v}_{\eta}\left\|\mathbf{v}_{\xi} \times \mathbf{v}_{\eta}\right\|^{-1}
$$

The tangential coordinates are then obtained as:

$$
\begin{gathered}
\mathbf{v}_{s}=\mathbf{v}_{\xi}\left\|\mathbf{v}_{\xi}\right\|^{-1} \\
\mathbf{v}_{t}=\mathbf{v}_{n} \times \mathbf{v}_{s}
\end{gathered}
$$


The components of $\mathbf{v}_{n}, \mathbf{v}_{s}$ and $\mathbf{v}_{t}$ represent the direction cosines of the local coordinate system in the global coordinate system at a material point $\bar{P} \in \bar{\Gamma}_{d}$. The director cosines define an orthogonal rotation tensor $\Theta_{m i}$ relating the local coordinate system to the fixed coordinate system.

Using the rotation tensor, the normal and tangential components of the displacement jump tensor expressed in terms of the displacement field in global coordinates are:

$$
\Delta_{m}=\Theta_{m i} \llbracket u_{i} \rrbracket
$$

where $\Delta_{m}$ is the displacement jump tensor in the local coordinate system.

\subsection{Constitutive laws}

A constitutive law relating the cohesive tractions, $\tau_{j}$, to the displacement jump in the local coordinates, $\Delta_{i}$, is required for modeling the behavior of the material discontinuity. The constitutive laws in the material discontinuity may be formally written as:

$$
\begin{gathered}
\tau_{j}=\tau\left(\Delta_{i}\right) \\
\dot{\tau}_{j}=D_{j i}^{\tan } \dot{\Delta}_{i}
\end{gathered}
$$

where $D_{j i}^{\mathrm{tan}}$ is the constitutive tangent stiffness tensor.

A new constitutive model relating the displacement jumps to the tractions, and based on Damage Mechanics is proposed.

The delamination model proposed follows the general formulation of Continuum Damage Models proposed by Simo and Ju [38]-[39] and Mazars [40]. 
The free energy per unit surface of the interface is defined as:

$$
\psi(\Delta, \mathrm{d})=(1-\mathrm{d}) \psi^{0}(\Delta)
$$

where $\mathbf{d}$ is a scalar damage variable, and $\psi^{0}$ is a convex function in the displacement jump space defined as:

$$
\psi^{0}(\Delta)=\frac{1}{2} \Delta_{i} D_{i j}^{0} \Delta_{j} \quad i=1,3 ; \quad j=1,3
$$

Negative values of $\Delta_{3}$ do not have any physical meaning because interpenetration is prevented by contact. Therefore, a modification of equation (15) is proposed to prevent interfacial penetration of the two adjacent layers after complete decohesion. The expression for the free energy proposed is:

$$
\psi(\Delta, \mathrm{d})=(1-\mathrm{d}) \psi^{0}\left(\Delta_{i}\right)-\mathrm{d} \psi^{0}\left(\bar{\delta}_{3 i}\left\langle-\Delta_{3}\right\rangle\right)
$$

where $\langle\cdot\rangle$ is the MacAuley bracket defined as $\langle x\rangle=\frac{1}{2}(x+|x|)$ and $\bar{\delta}_{i j}$ is the Kronecker delta. The constitutive equation for the interface is obtained by differentiating the free energy with respect to the displacement jumps:

$$
\tau_{i}=\frac{\partial \psi}{\partial \Delta_{i}}=(1-\mathrm{d}) D_{i j}^{0} \Delta_{j}-\mathrm{d} D_{i j}^{0} \bar{\delta}_{3 j}\left\langle-\Delta_{3}\right\rangle
$$

The undamaged stiffness tensor, $D_{i j}^{0}$, is defined as:

$$
D_{i j}^{0}=\bar{\delta}_{i j} K
$$

where the scalar parameter $K$ is a penalty stiffness. The constitutive equation 
can be written in Voigt notation as:

$$
\boldsymbol{\tau}=\left\{\begin{array}{c}
\tau_{1} \\
\tau_{2} \\
\tau_{3}
\end{array}\right\}=(1-\mathrm{d}) K\left\{\begin{array}{c}
\Delta_{1} \\
\Delta_{2} \\
\Delta_{3}
\end{array}\right\}-\mathrm{d} K\left\{\begin{array}{c}
0 \\
0 \\
\left\langle-\Delta_{3}\right\rangle
\end{array}\right\}
$$

The energy dissipation during damage evolution, $\Xi$, represented in Figure 4 for single-mode loading, can be obtained from:

$$
\Xi=-\frac{\partial \psi}{\partial \mathbf{d}} \dot{\mathrm{d}} \geq 0
$$

[Figure 4 about here]

The model defined by equation (18) is fully determined if the value of the damage variable $\mathrm{d}$ is evaluated at every time step of the deformation process. For that purpose, it is necessary to define a suitable norm of the displacement jump tensor, a damage criterion, and a damage evolution law, as will be described in the following sections.

\subsubsection{Norm of the displacement jump tensor}

The norm of the displacement jump tensor is denoted as $\lambda$ and is also called equivalent displacement jump norm. It is used to compare different stages of the displacement jump state so that it is possible to define such concepts as 'loading', 'unloading' and 'reloading'. The equivalent displacement jump is a 
non-negative and continuous function, defined as:

$$
\lambda=\sqrt{\left\langle\Delta_{3}\right\rangle^{2}+\left(\Delta_{\text {shear }}\right)^{2}}
$$

where $\Delta_{3}$ is the displacement jump in mode I, i.e., normal to midplane, and $\Delta_{\text {shear }}$ is the Euclidean norm of the displacement jump in mode II and in mode III:

$$
\Delta_{\text {shear }}=\sqrt{\left(\Delta_{1}\right)^{2}+\left(\Delta_{2}\right)^{2}}
$$

\subsubsection{Damage criterion}

The damage criterion is formulated in the displacement jump space. The form of this criterion is:

$$
F\left(\lambda^{t}, r^{t}\right):=\lambda^{t}-r^{t} \leq 0 \quad \forall t \geq 0
$$

where $t$ indicates the actual time and $r^{t}$ is the damage threshold for the current time. If $r^{0}$ denotes the initial damage threshold, then $r^{t} \geq r^{0}$ at every point in time. Damage initiation is produced when the displacement jump norm, $\lambda$, exceeds the initial damage threshold, $r^{0}$, which is a material property.

A fully equivalent expression for equation (24) that is more convenient for algorithmic treatment is [41]:

$$
\bar{F}\left(\lambda^{t}, r^{t}\right):=\mathrm{G}\left(\lambda^{t}\right)-\mathrm{G}\left(r^{t}\right) \leq 0 \quad \forall t \geq 0
$$

where $\mathrm{G}(\cdot)$ is a suitable monotonic scalar function ranging from 0 to $1 . \mathrm{G}(\cdot)$ will define the evolution of the damage value, and will be presented in the following section. 


\subsubsection{Damage evolution law}

The evolution laws for the damage threshold and the damage variable must be defined in the damage model. These laws are defined by the rate expressions:

$$
\begin{gathered}
\dot{r}=\dot{\mu} \\
\dot{\mathrm{d}}=\dot{\mu} \frac{\partial \bar{F}(\lambda, r)}{\partial \lambda}=\dot{\mu} \frac{\partial \mathrm{G}(\lambda)}{\partial \lambda}
\end{gathered}
$$

where $\dot{\mu}$ is a damage consistency parameter used to define loading-unloading conditions according to the Kuhn-Tucker relations:

$$
\dot{\mu} \geq 0 \quad ; \quad \bar{F}\left(\lambda^{t}, r^{t}\right) \leq 0 \quad ; \quad \dot{\mu} \bar{F}\left(\lambda^{t}, r^{t}\right)=0
$$

From the previous equations, it is easy to prove that the evolution of the internal variables can be integrated explicitly [38]:

$$
\begin{gathered}
r^{t}=\max \left\{r^{0}, \max \lambda^{s}\right\} \quad 0 \leq s \leq t \\
\mathrm{~d}^{t}=\mathrm{G}\left(r^{t}\right)
\end{gathered}
$$

which fully describes evolution of the internal variables for any loading-unloadingreloading situation. The scalar function $\mathrm{G}(\cdot)$ defines the evolution of the damage value. For a given mixed-mode ratio, $\beta$, the function proposed here is defined as:

$$
G(\lambda)=\frac{\Delta^{f}\left(\lambda-\Delta^{0}\right)}{\lambda\left(\Delta^{f}-\Delta^{0}\right)}
$$

Equation (31) defines the damage evolution law by means of a bilinear constitutive equation (see Figure 5), where $\Delta^{0}$ is the onset displacement jump, and it is equal to the initial damage threshold $r^{0}$. The initial damage threshold is obtained from the formulation of the initial damage surface or initial 
damage criterion. $\Delta^{f}$ is the final displacement jump, and it is obtained from the formulation of the propagation surface or propagation criterion.

[Figure 5 about here]

It is therefore necessary to establish the delamination onset and propagation surfaces for the complete definition of the damage model. Delamination onset and propagation surfaces and the damage evolution law fully define the constitutive equations.

The constitutive equations for the interfacial surface are normally developed in a phenomenological way, i.e., satisfying empirical relations that are obtained using experimental results. There are several types of constitutive equations used in decohesion elements: Tvergaard and Hutchinson [42] proposed a trapezoidal law, Cui an Wisnom [43] a perfectly plastic rule, Needleman first proposed a polynomial law, [28], and later an exponential law [29]. Goyal et al. [44] adopted Needleman's exponential law to account for load reversal without restoration of the cohesive state.

The law proposed here is a bilinear relation between the tractions and the displacement jumps [21],[24],[45]. The bilinear law is the most commonly used cohesive law due to its simplicity. One drawback of the bilinear law is that the traction-displacement jump relation is discontinuous at the peak value of the traction. The discontinuity in the traction-displacement jump relation can be avoided using continuous functions. However, even for such continuous functions, the discontinuity is unavoidable when modeling loading-unloading cycles. 
For a given mixed-mode ratio, $\beta$, defined as:

$$
\beta=\frac{\Delta_{\text {shear }}}{\Delta_{\text {shear }}+\left\langle\Delta_{3}\right\rangle}
$$

the bilinear constitutive equation is defined by a penalty parameter, $K$, the damage value, $\mathrm{d}$, the mixed-mode damage initiation, $\Delta^{0}$, and the total decohesion parameter, $\Delta^{f}$. These last two values are given by the formulation of the onset and the propagation criterion which takes into account the interaction between different modes, and their value depends on the mixed-mode ratio $\beta$. The penalty parameter $K$ assures a stiff connection between two neighboring layers before delamination initiation. The penalty parameter should be large enough to provide a reasonable stiffness but small enough to avoid numerical problems, such as spurious tractions oscillations [46], in a finite element analysis.

\section{Propagation criterion}

The criteria used to predict delamination propagation under mixed-mode loading conditions are usually established in terms of the components of the energy release rate and fracture toughness. It is assumed that when the energy release rate, $G$, exceeds the critical value, the critical energy release rate $G_{c}$, delamination grows.

The most widely used criterion to predict delamination propagation under mixed-mode loading, the "power law criterion" is normally established in terms of a linear or quadratic interaction between the energy release rates [48]. However, Camanho et al. [24] have shown that the expression proposed by Benzeggagh and Kenane [36] for the critical energy release rate for a mixedmode ratio is more accurate for epoxy and PEEK composites. The expression 
proposed by Benzeggagh and Kenane for the critical energy release rate $G_{c}$ is:

$$
G_{c}=G_{I c}+\left(G_{I I c}-G_{I c}\right)\left(\frac{G_{\text {shear }}}{G_{T}}\right)^{\eta}
$$

Delamination growth is produced when the total energy release rate $G$ is greater or equal than the critical value $G_{c}$ :

$$
G \geq G_{c}
$$

The energy release rate under mixed-mode loading is $G=G_{I}+G_{\text {shear }}$ where $G_{\text {shear }}=G_{I I}+G_{I I I}$ is the energy release rate for shear loading proposed by $\mathrm{Li}[49],[50]$.

The propagation surface in the displacement jump space is defined through the final displacements, which are obtained from the pure mode fracture toughness $\left(G_{I C}, G_{I I C}, G_{I I I C}\right)$ considering that the area under the traction-displacement jump curves is equal to the corresponding fracture toughness, i.e.:

$$
G_{C}=\frac{1}{2} K \Delta^{0} \Delta^{f}
$$

Using equation (35) in equation (33) the propagation criterion is obtained in the displacement jump space as:

$$
\Delta^{f}=\frac{\Delta_{3}^{0} \Delta_{3}^{f}+\left(\Delta_{\text {shear }}^{0} \Delta_{\text {shear }}^{f}-\Delta_{3}^{0} \Delta_{3}^{f}\right)\left(\frac{G_{\text {shear }}}{G_{T}}\right)^{\eta}}{\Delta^{0}}
$$

where $\Delta_{3}^{0}$ and $\Delta_{\text {shear }}^{0}$ are the pure mode onset displacement jumps and $\Delta_{3}^{f}$ and $\Delta_{\text {shear }}^{f}$ are the pure mode final displacement jumps. It is necessary to obtain the ratio $\frac{G_{\text {shear }}}{G_{T}}$ to fully define the final displacement jump. For a given mixed-mode ratio, $\beta$, the energy release rates are obtained from:

$$
G_{I}=\frac{1}{2} K\left(\Delta_{3}^{0}(\beta) \Delta_{3}^{f}(\beta)-\Delta_{3} \Delta_{3}^{f}(\beta)\right)
$$




$$
G_{\text {shear }}=\frac{1}{2} K\left(\Delta_{\text {shear }}^{0}(\beta) \Delta_{\text {shear }}^{f}(\beta)-\Delta_{\text {shear }} \Delta_{\text {shear }}^{f}(\beta)\right)
$$

where $\Delta_{\text {shear }}^{0}(\beta)$ and $\Delta_{3}^{0}(\beta)$ are respectively the shear and normal displacement jump corresponding to the onset of softening under mixed-mode loading, $\Delta_{\text {shear }}^{f}(\beta)$ and $\Delta_{3}^{f}(\beta)$ are the shear and normal displacement jump corresponding to the total decohesion under mixed-mode loading, and $\Delta_{\text {shear }}$ and $\Delta_{3}$ are the components of the current displacement jump.

From (32):

$$
\begin{aligned}
\Delta_{\text {shear }}^{0}(\beta) & =\Delta_{3}^{0}(\beta) \frac{\beta}{1-\beta} \\
\Delta_{\text {shear }}^{f}(\beta) & =\Delta_{3}^{f}(\beta) \frac{\beta}{1-\beta} \\
\Delta_{\text {shear }} & =\Delta_{3} \frac{\beta}{1-\beta}
\end{aligned}
$$

Using equations (39), (40), and (41) in (37) and (38), the ratio between $\frac{G_{\text {shear }}}{G_{T}}$ can be established in terms of $\beta$. Since the ratio $\frac{G_{\text {shear }}}{G_{T}}$ is only a function of the mixed-mode ratio $\beta$, henceforward this ratio is named as $B$ :

$$
B=\frac{G_{\text {shear }}}{G_{T}}=\frac{\beta^{2}}{1+2 \beta^{2}-2 \beta}
$$

\section{Initial damage surface}

Under pure mode I, mode II or mode III loading, delamination onset occurs when the corresponding interlaminar traction exceeds its respective maximum interfacial strength, $\tau_{3}^{0}, \tau_{2}^{0}, \tau_{1}^{0}$. Under mixed-mode loading, an interaction between modes must be taken into account. Few models take into account the interaction of the traction components in the prediction of damage onset. The models that account for the interaction of the traction components are usually 
based on Ye's criterion [51], using a quadratic interaction of the tractions:

$$
\left(\frac{\left\langle\tau_{3}\right\rangle}{\tau_{3}^{0}}\right)^{2}+\left(\frac{\tau_{2}}{\tau_{2}^{0}}\right)^{2}+\left(\frac{\tau_{1}}{\tau_{1}^{0}}\right)^{2}=1
$$

However, experimental data for the initiation of delamination under mixedmode is not readily available and, consequently, failure criteria that can predict the initiation have not been fully validated.

The criterion for propagation is often formulated independently of the criterion for initiation. In this paper, a link between propagation and initiation is proposed. Since delamination is a fracture process, the initiation criterion proposed in this paper evolves from the propagation criterion and the damage evolution law. The isodamage surface for a damage value equal to 1 corresponds to the propagation surface obtained from equation (33). Then, the isodamage surface for a damage value equal to 0 is the initial damage surface. With these assumptions, the criterion for delamination initiation proposed here is:

$$
\left(\tau^{0}\right)^{2}=\left(\tau_{3}\right)^{2}+\left(\tau_{1}\right)^{2}+\left(\tau_{2}\right)^{2}=\left(\tau_{3}^{o}\right)^{2}+\left(\left(\tau_{\text {shear }}^{o}\right)^{2}-\left(\tau_{3}^{o}\right)^{2}\right) B^{\eta}
$$

In the displacement jump space, the criterion becomes:

$$
\left(\Delta^{0}\right)^{2}=\left(\Delta_{3}\right)^{2}+\left(\Delta_{1}\right)^{2}+\left(\Delta_{2}\right)^{2}=\left(\Delta_{3}^{0}\right)^{2}+\left(\left(\Delta_{\text {shear }}^{0}\right)^{2}-\left(\Delta_{3}^{0}\right)^{2}\right) B^{\eta}
$$

The initiation criterion developed here and summarized by equation (44) is compared with Ye's criterion and with a maximum traction criterion that does not take into account interaction between the tractions. The surfaces obtained by the different criterion are represented in Figure 6 . The values predicted by the new criterion are very close to Ye's criterion, that has been successfully 
used in previous investigations [24].

[Figure 6 about here]

The formulation presented assures a smooth transition for all mixed-mode ratios between the initial damage surface to the propagation surface through damage evolution. If the loading mode changes, the formulation presented avoids the restoration of the cohesive state and assures that the energy dissipation is always positive.

The evolution of the damage surface from the damage initiation surface to the propagation surface is represented in Figure 7, for positive values of displacement jumps.

[Figure 7 about here]

\subsection{Formulation of the constitutive tangent tensor}

The constitutive tangent tensor needs to be defined for the numerical implementation of the proposed model. The constitutive tangent tensor is obtained from the differentiation of the secant equation (18):

$$
\dot{\tau}_{i}=D_{i j} \dot{\Delta}_{j}-\bar{\delta}_{i j} K\left[1+\bar{\delta}_{3 j} \frac{\left\langle-\Delta_{j}\right\rangle}{\Delta_{j}}\right] \Delta_{j} \dot{\mathrm{d}}
$$

where $D_{i j}$ is defined as:

$$
D_{i j}=\bar{\delta}_{i j} K\left[1-\mathrm{d}\left(1+\bar{\delta}_{3 j} \frac{\left\langle-\Delta_{j}\right\rangle}{\Delta_{j}}\right)\right]
$$


The evolution of the damage variable $d$ only occurs for loading situations. Then, the evolution of the damage variable can be written as:

$$
\dot{\mathrm{d}}=\left\{\begin{array}{cc}
\dot{\mathrm{G}}(\lambda)=\frac{\partial \mathrm{G}(\lambda)}{\partial \lambda} \dot{\lambda} & , r<\lambda<\Delta^{f} \\
0 & , r>\lambda \text { or } \Delta^{f}<\lambda
\end{array}\right.
$$

where the variation of the function $G$ is obtained assuming that the variation of the final displacement jump $\Delta^{f}$ and the onset displacement jump $\Delta^{0}$ with the mixed-mode ratio $\beta$ are not significant for the time increment taken:

$$
\frac{\partial \mathrm{G}(\lambda)}{\partial \lambda}=\frac{\Delta^{f} \Delta^{0}}{\Delta^{f}-\Delta^{0}} \frac{1}{\lambda^{2}}
$$

The evolution of the displacement norm is obtained from equation (22):

$$
\dot{\lambda}=\frac{\partial \lambda}{\partial \Delta_{k}} \dot{\Delta}_{k}=\frac{\Delta_{k}}{\lambda}\left(1+\bar{\delta}_{3 k} \frac{\left\langle-\Delta_{k}\right\rangle}{\Delta_{k}}\right) \dot{\Delta}_{k}
$$

Using equations (48) through (50), equation (46) can be written as:

$$
\begin{gathered}
\dot{\tau}_{i}=D_{i j}^{\tan } \dot{\Delta}_{j} \\
D_{i j}^{\tan }= \begin{cases}\left\{D_{i j}-K\left[1+\bar{\delta}_{3 j} \frac{\left\langle-\Delta_{j}\right\rangle}{\Delta_{j}}\right]\left[1+\bar{\delta}_{3 i} \frac{\left\langle-\Delta_{i}\right\rangle}{\Delta_{i}}\right] H \Delta_{i} \Delta_{j}\right\} & , r<\lambda<\Delta^{f} \\
D_{i j} & , r>\lambda \text { or } \Delta^{f}<\lambda\end{cases}
\end{gathered}
$$

where $H$ is a scalar value given by:

$$
H=\frac{\Delta^{f} \Delta^{0}}{\Delta^{f}-\Delta^{0}} \frac{1}{\lambda^{3}}
$$




\section{$3 \quad$ Finite element discretization - computational model}

To transform the strong form of the boundary value problem into a weak form better suited for finite element computations, the velocities $v_{i}$ must belong to the set $\mathcal{U}$ of the kinematically admissible velocity field which allows for discontinuous velocities across the boundary $\Gamma_{d}$ of the delamination.

The spaces for the test functions and trial functions are defined as:

$$
\begin{aligned}
& \delta v_{i}(\mathbf{X}) \in \mathcal{U}_{0}, \quad \mathcal{U}_{0}=\left\{\delta v_{i} \mid \delta v_{i} \in C^{0}(\mathbf{X}), \delta v_{i}=0 \quad \text { on } \Gamma_{v_{i}}\right\} \\
& v_{i}(\mathbf{X}, t) \in \mathcal{U}, \quad \mathcal{U}=\left\{v_{i} \mid v_{i} \in C^{0}(\mathbf{X}), v_{i}=\bar{v}_{i} \text { on } \Gamma_{v_{i}}\right\}
\end{aligned}
$$

The space of velocities in $\mathcal{U}$ are the kinematically admissible velocities or compatible velocities. The space $\mathcal{U}$ satisfies the continuity conditions required for compatibility and the displacement boundary conditions.

Considering Figure 2, the weak form of the momentum equation is obtained as:

$$
\sum_{\Omega_{ \pm}} \int_{\Omega_{ \pm}}\left(\frac{\partial \sigma_{i j}}{\partial x_{j}}+\rho b_{i}\right) \delta v_{i} d \Omega_{ \pm}=0 \forall v_{i} \in \mathcal{U}
$$

where $b_{i}$ are the body forces and $\rho$ is the density of the material

Using the decomposition of the velocity gradient and the traction continuity condition, the weak form of the momentum equation in an updated Lagrangian formulation is obtained as:

$$
\begin{array}{r}
\int_{\Gamma_{d}} t_{i} \delta \llbracket v_{i} \rrbracket d \Gamma_{d}+\sum_{\Omega_{ \pm}} \int_{\Omega_{ \pm}} \delta D_{i j} \sigma_{i j} d \Omega_{ \pm}= \\
\sum_{\Gamma_{ \pm}} \int_{\Gamma_{ \pm}} n_{j}\left(\delta v_{i} \sigma_{j i}\right) d \Gamma_{ \pm}+\sum_{\Omega_{ \pm}} \int_{\Omega_{ \pm}} \delta v_{i} \rho b_{i} d \Omega_{ \pm} \quad \forall v_{i} \in \mathcal{U}
\end{array}
$$


where $t_{i}$ is the traction tensor, $\sigma_{i j}$ is the Cauchy stress tensor, and $D_{i j}$ is the rate of deformation tensor. From equation (57), it is clear that the tractions occurring at the cohesive interface are work-conjugate with the displacement jumps.

The discretization of the domain is performed by the discretization of the whole domain $\Omega$ with standard volume elements. However, the surfaces surrounding the potential delamination $\Gamma_{d}$ are discretized with decohesion elements [24]. The discretized formulation is divided in the two domains considering no formal coupling between the continuous and the discontinuous parts of the deformation in the expression for the free energy of the interface [53].

\subsection{Discretization of the interfacial surface}

The displacements and displacement gradients for the decohesion elements are approximated as:

$$
\begin{gathered}
\left.u_{i}\right|_{\Omega_{e}}=N_{K}^{e} q_{K i}^{e} \\
\left.\llbracket u_{i} \rrbracket\right|_{\Omega_{e}}=\bar{N}_{K}^{e} q_{K i}^{e}
\end{gathered}
$$

with:

$$
\bar{N}_{K}^{e}=\left\{\begin{array}{cc}
N_{K}^{e} & K \in \Gamma_{d}^{+} \\
-N_{K}^{e} & K \in \Gamma_{d}^{-}
\end{array}\right.
$$

where $q_{K i}^{e}$ is the displacement in the $i$ direction of the $K$ node of the element $e, N_{K}^{e}$ are standard Lagrangian shape functions [52]. $\bar{N}_{K}^{e}$ are Lagrangian shape functions defined for the decohesion elements [24].

According to equation (58), the displacement field, $u_{i}$, and the undeformed material coordinate, $X_{i}$, associated with the surfaces $\Gamma_{d^{ \pm}}$are interpolated as 
follows:

$$
\begin{gathered}
u_{i}^{ \pm}=N_{K} q_{K i}^{ \pm} \\
X_{i}^{ \pm}=N_{K} p_{K i}^{ \pm}
\end{gathered}
$$

where $q_{K i}^{ \pm}$are the nodal displacement vectors and $p_{K i}^{ \pm}$are the undeformed material nodal coordinate vector. Note that the values of $p_{K i}^{-}$and $p_{K i}^{+}$can be different in the case that an initial crack exists. Using these equations, the material coordinates of the interfacial midsurface are:

$$
\bar{x}_{i}=\frac{1}{2} N_{K i}\left(p_{K i}^{+}+p_{K i}^{-}+q_{K i}^{+}+q_{K i}^{-}\right)
$$

The components of the two vectors that define the tangential plane can be written as:

$$
\begin{aligned}
& v_{\eta_{i}}=\bar{x}_{i, \eta}=N_{K i, \eta} \frac{1}{2}\left(p_{K i}^{+}+p_{K i}^{-}+q_{K i}^{+}+q_{K i}^{-}\right) \\
& v_{\xi_{i}}=\bar{x}_{i, \xi}=N_{K i, \xi} \frac{1}{2}\left(p_{K i}^{+}+p_{K i}^{-}+q_{K i}^{+}+q_{K i}^{-}\right)
\end{aligned}
$$

Using (59) and (12), the displacement jump can then be obtained in local coordinates as:

$$
\Delta_{m}=\Theta_{i m} \bar{N}_{K} q_{K i}=\bar{B}_{i m K} q_{K i}
$$

The contribution of a decohesion element for the internal load vector is given by:

$$
f_{i K}^{i n t}=\int_{\Gamma_{d}} \tau_{n} \bar{B}_{i n K} d \Gamma_{d}
$$

with $\bar{B}_{i n K}=\Theta_{i n} \bar{N}_{K}^{e}$.

The softening nature of the decohesion element constitutive equation causes difficulties in obtaining a converged solution for the non-linear problem when using Newton-Raphson iterative method. In particular, quadratic convergence 
is not assured because the residual vector is not continuously differentiable with respect to the nodal displacements.

The tangent stiffness matrix stems from the linearization of the internal force vector and it is obtained using Taylor's series expansion about the approximation $q_{K i}[25]$. Taking into account that the calculation of the geometric terms of the tangent stiffness matrix is computationally very intensive, these terms are neglected. The tangent stiffness matrix, $K_{r Z i K}$, for the decohesion element is therefore approximated as:

$$
K_{r Z i K} \approx \int_{\Gamma_{d}} \bar{B}_{j r Z} D_{n j}^{\tan } \bar{B}_{i n K} d \Gamma_{d}
$$

where $D_{i j}^{\tan }$ is the material tangent stiffness matrix, or constitutive tangent tensor defined in 2.4.

\section{Comparison with experimental studies}

The formulation proposed here was implemented in the ABAQUS Finite Element code [54] as a user-written element subroutine (UEL).

To verify the element under different loading conditions, the numerical predictions were compared with experimental data obtained for composite test specimens and aircraft subcomponents. The double cantilever beam (DCB) test, the end notched flexure (ENF) test, and mixed-mode bending (MMB) tests in PEEK/AS4, a thermoplastic matrix composite material, were simulated.

The debonding of a composite co-cured skin-stiffener subcomponent loaded under tension was simulated, and the numerical results were compared with 
experimental data.

\subsection{Mode I, mode II and mixed-mode I and II delamination growth for a PEEK composite}

The most widely used specimen for mixed-mode fracture is the mixed-mode bending (MMB) specimen shown in Figure 8, which was proposed by Reeder and Crews [55]-[57].

[Figure 8 about here]

The main advantages of the MMB test method are the possibility of using virtually the same specimen configuration as for mode I tests, and the capability of obtaining different mixed-mode ratios, ranging from pure mode I to pure mode II, by changing the length $c$ of the loading lever shown in Figure 8.

An 8-node decohesion element is used to simulate DCB, ENF and MMB tests in unidirectional AS4/PEEK carbon-fiber reinforced composite. The specimens simulated are 102-mm-long, 25.4-mm-wide, with two 1.56-mm-thick arms. The material properties are shown in Table 1 , and a stiffness $K=10^{6}$ $\mathrm{N} / \mathrm{mm}^{3}$ is used.

[Table 1 about here]

The experiments used to assess the accuracy of the model proposed were performed by Reeder [55]-[57]. The experimental tests were performed at different

$\frac{G_{I I}}{G_{T}}$ ratios, ranging from pure mode I loading to pure mode II loading. The 
initial delamination length of the specimens $\left(a_{0}\right)$ and the mixed-mode fracture toughness obtained experimentally are shown in Table 2 .

[Table 2 about here]

Models using 150 decohesion elements along the length of the specimens, and 4 decohesion elements along the width, were created to simulate the ENF and MMB test cases. The initial size of the delamination is simulated by placing open decohesion elements along the length corresponding to the initial delamination of each specimen (see Table 2). These elements are capable of dealing with the contact conditions occurring for mode II or mixed-mode I and II loading, therefore avoiding interpenetration of the delamination faces. The model of the DCB test specimen uses 102 decohesion elements along the length of the specimen.

The different $G_{I I} / G_{I}$ ratios are simulated by applying different loads at the middle and at the end of the test specimen. The analytical determination of the middle and end loads for each mode ratio is presented in [24].

The experimental results relate the load to the displacement of the point of application of the load P in the lever (load-point displacement, Figure 8). Since the lever is not simulated, it is necessary to determine the loadpoint displacement from the displacement at the end and at the middle of the specimen using the analytical procedure described in [24].

The B-K parameter, $\eta=2.284$, is calculated by applying a least-squares fit to the experimental data shown in Table 2. 
Figures 9 to 13 show the numerical predictions and the experimental data for all the test cases simulated.

[Figure 9 about here]

[Figure 10 about here]

[Figure 11 about here]

[Figure 12 about here]

[Figure 13 about here]

Table 3 shows the comparison between the predicted and experimentally determined maximum loads.

[Table 3 about here]

It can be concluded that a good agreement between the numerical predictions and the experimental results is obtained. The largest difference $(-8.1 \%)$ corresponds to the case of an MMB test specimen with $\frac{G_{I I}}{G_{T}}=20 \%$. This fact is not surprising, since the largest difference between the fracture toughness experimentally measured and the one predicted using the B-K criterion occurs for $\frac{G_{I I}}{G_{T}}=20 \%$. 


\subsection{Skin-stiffener co-cured structure}

Most composite components in aerospace structures are made of panels with co-cured or adhesively bonded frames and stiffeners. Testing of stiffened panels has shown that bond failure at the tip of the stiffener flange is a common failure mode. Comparatively simple specimens consisting of a stringer flange bonded onto a skin have been developed by Krueger et al. to study skin/stiffener debonding [58]. The configuration of the specimens studied by Krueger is shown in Figure 14.

[Figure 14 about here]

The specimens are $203 \mathrm{~mm}$-long, $25.4 \mathrm{~mm}$-wide. Both skin and flange were made from IM6/3501-6 graphite/epoxy prepreg tape with a nominal ply thickness of $0.188 \mathrm{~mm}$. The skin lay-up consisting of 14 plies was $\left(0^{\circ} / 45^{\circ} / 90^{\circ} /-\right.$ $\left.45^{\circ} / 45^{\circ} /-45^{\circ} / 0^{\circ}\right)_{S}$ and the flange lay-up consisting of 10 plies was $\left(45^{\circ} / 90^{\circ} /-\right.$ $\left.45^{\circ} / 0^{\circ} / 90^{\circ}\right)_{S}$.

The properties of the unidirectional graphite/epoxy and the properties of the interface reported in reference [58] are shown in Tables 4 and 5, respectively.

[Table 4 about here]

[Table 5 about here]

The parameter for the B-K criterion is taken from test data for AS4/3501-625 as $\eta=1.45$, and a stiffness $K=10^{6} \mathrm{~N} / \mathrm{mm}^{3}$ is used. 
To keep the modeling difficulties low and the approach applicable to larger problems, the model that was developed uses only two brick elements through the thickness of the skin, and another two through the flange. The complete model consists of 1,002 three-dimensional 8-node elements and 15,212 degrees of freedom. To prevent delamination from occurring at both ends of the flange simultaneously, model symmetry was reduced by modeling the tapered end of the flange with a refined mesh on one side and a coarser mesh on the other. Unlike the previous examples, this model does not contain any pre-existing delaminations.

Residual thermal effects in the composite plies are simulated by performing a thermal analysis step before the mechanical loads are applied. The same coefficients of thermal expansion $\left(\alpha_{11}=-2.4 \times 10^{-8} /{ }^{\circ} \mathrm{C}\right.$ and $\left.\alpha_{22}=3.7 \times 10^{-5} /{ }^{\circ} \mathrm{C}\right)$ are applied to the skin and the flange, and the temperature difference between the room and curing temperatures is $\Delta \mathrm{T}=-157^{\circ} \mathrm{C}$. The flange has more $90^{\circ}$ plies than $0^{\circ}$ plies, and the skin is quasi-orthotropic, so it is expected that residual thermal stresses are present at their interface at room temperature.

Deformed plots of the finite element model immediately before and after flange separation are shown in Figure 15.

[Figure 15 about here]

It can be observed that only the refined end of the flange separates. It is worth noticing that the debond growth is not symmetric across the width: the debond initiates on the left corner of the flange shown on the bottom left of Figure 15 due to the lack of symmetry introduced by the terminated plies at the flange tapered ends. This behavior was also observed in the experiments 
$[58]$.

Figure 16 shows the load-extensometer measurement relation obtained in 4 experiments and the corresponding numerical prediction. Debond is detected in the experiments by the discontinuities in the load-displacement relation.

Table 6 compares the average of the measured debond loads with the numerical predictions.

[Figure 16 about here]

[Table 6 about here]

It can be observed that good accuracy in the prediction of the debond loads is obtained. The predicted stiffness of the specimen is also in good agreement with the experimental data. The stiffening effect detected in the experiments, Figure 16, is due to the extensometer rotation as a result of specimen bending. Although specimen bending is properly represented by the numerical model, the extensometer measurement calculated from the numerical model does not account for the rotation of the extensometer.

\section{Concluding remarks}

A thermodynamically consistent model for the simulation of progressive delamination based on Damage Mechanics was presented. A constitutive equation for the interface was derived from the free energy of the interface. The resulting damage model simulates delamination onset and delamination prop- 
agation. The constitutive equation proposed uses a single scalar variable to track the damage at the interface under general loading conditions. A new initiation criterion that evolves from the Benzeggagh-Kenane propagation criterion has been developed to assure that the model accounts for changes in the loading mode in a thermodynamically consistent way and avoids restoration of the cohesive state. The damage model was implemented in a finite element model. The material properties required to define the element constitutive equations are the interlaminar fracture toughnesses, the penalty stiffness, and the strengths of the interface. In addition, a material parameter $\eta$, which is determined from standard delamination tests, is required for the BenzeggaghKenane mode interaction law.

Two examples were presented that test the accuracy of the method. In the first example, the simulations of the DCB, ENF and MMB tests represent cases of single-mode and mixed-model delamination. A composite skin-stiffener cocured sub-component was also simulated, and the model predictions were compared with available experimental data.

The examples analyzed are in good agreement with the test results, and they indicate that the proposed formulation can predict the strength of composite structures that exhibit progressive delamination. 


\section{References}

[1] Camanho, P.P., Matthews, F.L., Delamination onset prediction in mechanically fastened joints in composite laminates. Journal of Composite Materials, 33, 906-27, 1999.

[2] Dávila, C.G., Johnson, E.R., Analysis of delamination initiation in postbuckled dropped-ply laminates. AIAA Journal, 31, 721-727, 1993.

[3] Liu, S., Quasi-impact damage initiation and growth of thick-section and toughened composite material. Int J Solids Struct, 31, 3079-3098, 1999.

[4] Zou, Z., Reid, S.R., Li, S., Soden, P.D., Modelling interlaminar and intralaminar damage in filament wound pipes under quasi-static indentation. J. Compos. Mater., 36, 477-499, 2002.

[5] Irwin, G.R., Analysis of stresses and strains near the end of a crack transversing a plate, J. Appl. Mech., 24, 361-366, 1957.

[6] Rybicki, E.F., Kanninen, M.F., A finite element calculation of stress intensity factors by a modified crack closure integral. Engineering Fracture Mechanics, 9, 931-938, 1977.

[7] Raju, I.S., Calculation of strain-energy release rates with higher order and singular finite elements. Engineering Fracture Mechanics, 38(3),251-274, 1987.

[8] Zou, Z., Reid, S.R., Li, S., Soden, P.D., Mode separation of energy release rate for delamination in composite laminates using sublaminates. Int. J. Solids Struct., 38, 2597-2613, 2001.

[9] Krueger, R., The virtual crack closure technique: history, approach and applications. NASA/CR-2002-211628, 2002.

[10] Rice, J.R., A path independent integral and the approximate analysis of strain concentration by notches and cracks. J. Appl. Mech, 35, 379-386, 1968. 
[11] Hellen, T.K., On the method of the virtual crack extension. Int. J. Num. Meth. Eng. 9, 187-207, 1975.

[12] Parks, D.M., A stiffness derivative finite element technique for determination of crack tip stress intensity factors. Int. J. Fract. 10(4),487-502,1974.

[13] Griffith, A.A., The phenomena of rupture and flow in solids. Philosophical transactions of the Royal Society, London, Series A. 221, 163-198, 1921.

[14] Dugdale, D.S., Yielding of steel sheets containing slits. J. Mech. Phys. Sol. 8,100-104, 1960.

[15] Barenblatt, G., The mathematical theory of equilibrium cracks in brittle fracture. Adv. Appl. Mech. 7, 55-129, 1962.

[16] Hillerborg, A., Modéer, M., Petersson, P.E., Analysis of crack formation and crack growth in concrete by means of fracture mechanics and finite elements. Cement and Concrete Research. 6, 773-782, 1976.

[17] Allix, O., Ladeveze, P., Corigliano, A., Damage analysis of interlaminar fracture specimens. Comp. Struc. 31, 66-74, 1995.

[18] Allix, O., Corigliano, A., Modelling and simulation of crack propagation in mixed-modes interlaminar fracture specimens. Int. J. Fract. 77,111-140, 1996.

[19] Schellekens, J.C.J., de Borst, R., A nonlinear finite-element approach for the analysis of mode-I free edge delamination in composites. Int. J. Solids Struc., 30(9), 1239-1253, 1993.

[20] Chaboche, J.L., Girard, R., Schaff, A., Numerical analysis of composite systems by using interphase/interface models. Comp. Mech. 20, 3-11, 1997.

[21] Mi, U., Crisfield, M.A., Davies, G.A.O., Progressive delamination using interface elements. J. Compos. Mater, 32, 1246-1272, 1998. 
[22] Chen, J., Crisfield, M.A., Kinloch, A.J., Busso, E.P., Matthews, F.L., and Qiu, Y., Predicting Progressive Delamination of Composite Material Specimens Via Interface Elements. Mechanics of Composite Materials and Structures, 6, 301317,1999 .

[23] Alfano, G., Crisfield, M.A., Finite element interface models for the delamination analysis of laminated composites: mechanical and computational issues. Int. J. Numer. Meth. Engng., 77(2), 111-170, 2001.

[24] Camanho, P.P., Dávila, C.G., de Moura, M.F., Numerical Simulation of MixedMode Progressive Delamination in Composite Materials. Journal of Composite Materials, 37 (16), 1415-1438, 2003.

[25] Goyal-Singhal, V., Johnson, E.R., Dávila, C.G., Irreversible constitutive law for modeling the delamination process using interfacial surface discontinuities. Composite Structures, 64, 91-105, 2004.

[26] Bažant, Z.P., Jirásek, M., Nonlocal integral formulations of plasticity and damage: survey of progress. J. Engineering Mechanics, 128, 1119-1149, 2002.

[27] Tvergaard, V., Hutchinson, J.W., The influence of plasticity on mixed-mode interface toughness, J. Mech. Phys. Solids, 41, 119-1135, 1993.

[28] Needleman, A., A continuum model for void nucleation by inclusion debonding. J. Appl. Mech, 54, 525-532, 1987.

[29] Xu, X-P, Needleman, A., Numerical simulations of fast crack growth in brittle solids. J. Mech. Phys. Solids, 42 (9), 1397-1434, 1994.

[30] Yan, A.M., Marechal, E., Ngyen-Dang, H., A finite-element model of mixed-mode delamination in laminated composites with and R-curve effect. Composites Science and Technology, 61, 1413-1427, 2001.

[31] Li, D., Wisnom, M., Modelling damage initiation and propagation composites 
using interface elements. Presented at the Computer Aided Design in Composite Material Technology- International Conference. Southampton, UK, 1994.

[32] Petrossian, Z., Wisnom, M.R., Prediction of Delamination Initiation and Growth From Discontinuous Plies Using Interface Elements, Composites-Part A, 29, 503-515, 1998.

[33] Ladevèze, P., Allix, O., Gornet, L., Lévêque, D., et al., A computational damage mechanics approach for laminates: identification and comparisons with experimental results, in Damage Mechanics in Engineering Materials, G.Z. Voyiadkjis, J.W.W. Ju, and J.L. Chaboche, Editors. Elsevier Science B.V. 481$499,1998$.

[34] Borg, R., Nilsson, L. Simonsson, K., Modeling of delamination using a discretized cohesive zone and damage formulation. Composites Science and Technology, 62, 1299-1314, 2002.

[35] Jansson, N.E., Larsson, R., A damage model for simulation of mixed-mode delamination growth. Composite Structures, 53, 409-417, 2001.

[36] Benzeggagh, M.L., Kenane, M., Measurement of Mixed-Mode delamination Fracture Toughness of Unidirectional Glass/Epoxy Composites With MixedMode Bending Apparatus. Composites Science and Technology, 49, 439-49, 1996.

[37] Ortiz, M., Pandolfi, A., Finite-deformation irreversible cohesive elements for three- dimensional crack propagation analysis. International Journal for Numerical Methods in Engineering, 44, 1267-82, 1999.

[38] Simo, J., Ju, J. W., Strain- and stress- based continuum damage model- I. Formulation. International Journal Solids Structures, 23, 821-840, 1987.

[39] Simo, J., Ju, J. W., Strain- and stress- based continuum damage model- II. Computational aspects. International Journal Solids Structures, 23, 841-869, 
1987.

[40] Mazars, J., Mechanical Damage and Fracture of Concrete Structures. Advances in Fracture Research (Fracture 81), 4, 1499-1506. Pergamon Press, Oxford, 1982.

[41] Oliver, J., Cervera, M., Oller, S., Lubliner, J., Isotropic damage models and smeared crack analysis of concrete. Second International Conference on Computer Aided Analsis and Design of Concrete Structures, 2, 945-958, 1990.

[42] Tvergaard, V., Hutchinson, J.W., The relation between crack growth resistance and fracture process parameters in elastic-plastic solids. J. Mech. Phys. Solids, 40, 1377-1397, 1992.

[43] Cui, W., Wisnom, M. R., A combined stress-based and fracture-mechanicsbased model for predicting delamination in composites. Composites, 24, 467474, 1993.

[44] Goyal-Singhal, V., Johnson, E.R., Dávila, C.G, and Jaunky, N., An Irreversible Constitutive Law for Modeling the Delamination Process Using Interface Elements. 43rd AIAA/ASME/ASCE/AHS/ASC Structures, Structural Dynamics and Materials Conference, Colorado,USA, 2002.

[45] Reddy Jr., E.D., Mello, F.J., Guess, T.R., Modeling the Initiation and Growth of Delaminations in Composite Structures. Journal of Composite Materials, 31, 812-831, 1997.

[46] Schellekens, J.C.J., de Borst R., On the numerical integration of interface elements. Int. J. Numer. Meth. Engng., 36: 43-66, 1992.

[47] Camanho, P.P., Dávila, C.G., Pinho, S.T., Fracture analysis of composite cocured structural joints using decohesion elements. Fatigue Fract Engng Mater Struct, 27,745-757, 2004. 
[48] Wu, E.M., Reuter Jr., R.C., Crack extension in fiberglass reinforced plastics. T. \& AM Report No. 275. University of Illinois, 1965.

[49] Li, J., Sen, J.K., Analysis of frame-to-skin joint pull-off tests and prediction of the delamination failure. 42nd AIAA/ASME/ASCE/AHS/ASC Structures, Structural Dynamics and Materials Conference, Seattle, WA, USA, 2000.

[50] Li, J., Three-Dimensional effects in the prediction of flange delamination in composite skin-stringer pull-off specimens. 15th Conference of the American Society for Composites Texas, USA, 2000.

[51] Ye, L., Role of Matrix Resin in Delamination Onset and Growth in Composite Laminates, Composites Science and Technology, 33, 257-277, 1988.

[52] Belytschko, T., Liu, W.K., Moran, B., Nonlinear Finite Elements for Continua and Structures. John Wiley ES Sons, LTD, 2001.

[53] Larsson, R., Jansson, N., Geometrically non-linear damage interface based on regularized strong discontinuity. Int. J. Numer. Meth Engng, 54, 473-497, 2002.

[54] Hibbitt, Karlsson, Sorensen. ABAQUS 6.2 User's Manuals. Pawtucket, USA, 1996.

[55] Crews, J.H., Reeder, J.R., A Mixed-Mode Bending Apparatus for Delamination Testing. NASA TM 100662, 1988.

[56] Reeder, J.R., Crews, J.H., Mixed-Mode Bending Method for Delamination Testing. AIAA Journal 28, 1270-1276, 1990.

[57] Reeder, J.R., Crews, J.H., Nonlinear Analysis and Redesign of the Mixed-Mode Bending Delamination Test. NASA TM 102777, 1991.

[58] Krueger, R., Cvitkovich, M.K., O’Brien, T.K., Minguet, P.J., Testing and analysis of composite skin/stringer debonding under multi-axial loading. Journal of Composite Materials, 34, 1263-1300, 2000. 


\section{List of Figures}

1 Restoration of the cohesive state for delamination propagation under variable-mode ratio.

2 Body $\Omega$ crossed by a material discontinuity $\Gamma_{d}$ in the undeformed configuration.

3 Interfacial surface deformation.

$4 \quad$ Energy dissipation during damage evolution.

5 A bilinear constitutive equation for the decohesion element for a mixed mode loading situation.

6 Comparison between Ye's criterion, a maximum traction criterion and the new proposed criterion.

7 Damage evolution surface in the relative displacements space.

$8 \quad$ MMB test specimen.

$9 \quad$ Numerical and experimental results- pure mode I loading.

10 Numerical and experimental results- mixed mode I and II loading with $\mathrm{G}_{I I} / \mathrm{G}_{T}=20 \%$.

11 Numerical and experimental results- mixed mode I and II loading with $\mathrm{G}_{I I} / \mathrm{G}_{T}=50 \%$.

12 Numerical and experimental results- mixed mode I and II loading with $\mathrm{G}_{I I} / \mathrm{G}_{T}=80 \%$. 
13 Numerical and experimental results- pure mode II loading.

14 Skin-stiffener test specimen.

15 Skin-Stiffener debonding.

16 Experimental and numerical load-extensometer displacement relations. 


\section{List of Tables}

$1 \quad$ Ply properties. $\quad 50$

2 Experimental data. $\quad 50$

3 Maximum loads. $\quad 51$

4 Material properties for IM6-3501-6 unidirectional graphite $\begin{array}{ll}\text { epoxy. } & 51\end{array}$

$5 \quad$ Interface properties. $\quad 52$

$6 \quad$ Comparison between experimental and numerical results. 52 


\section{Figures}

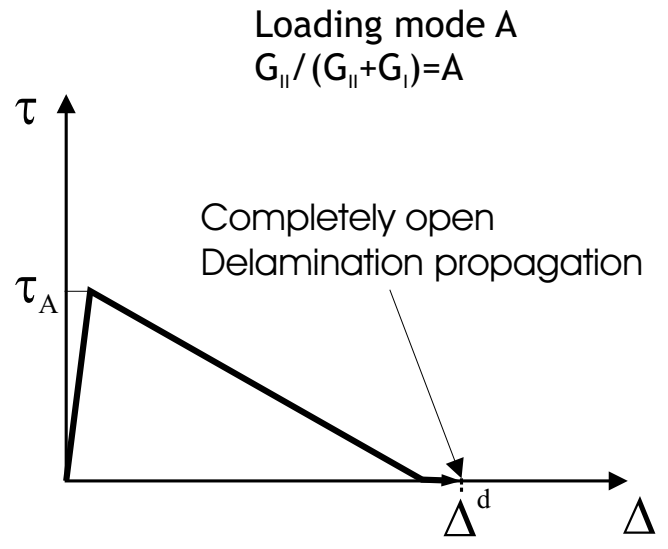

a)
Loading mode $B$

$\mathrm{G}_{\|} /\left(\mathrm{G}_{\|}+\mathrm{G}_{1}\right)=\mathrm{B}$

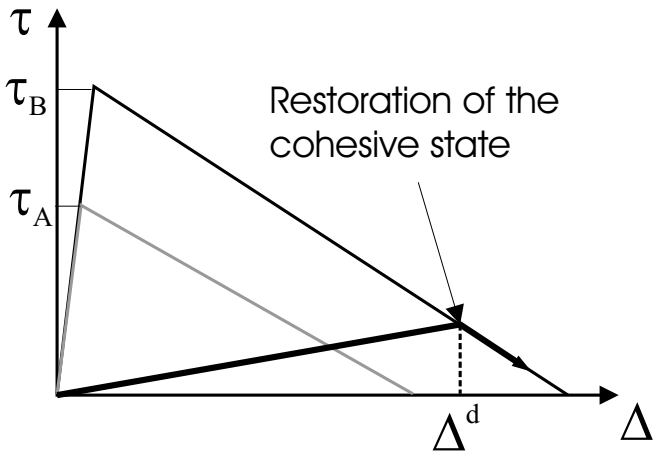

b)

Fig. 1. Restoration of the cohesive state for delamination propagation under variable-mode ratio. 


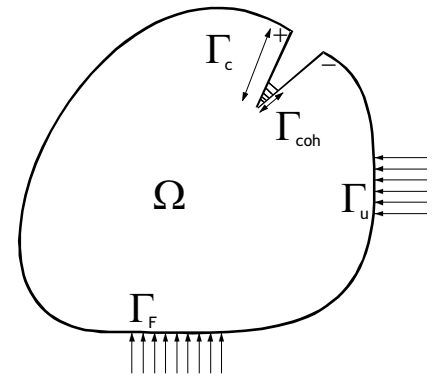

(a)

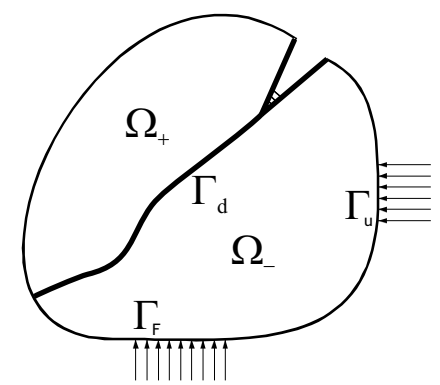

(b)

Fig. 2. Body $\Omega$ crossed by a material discontinuity $\Gamma_{d}$ in the undeformed configuration.

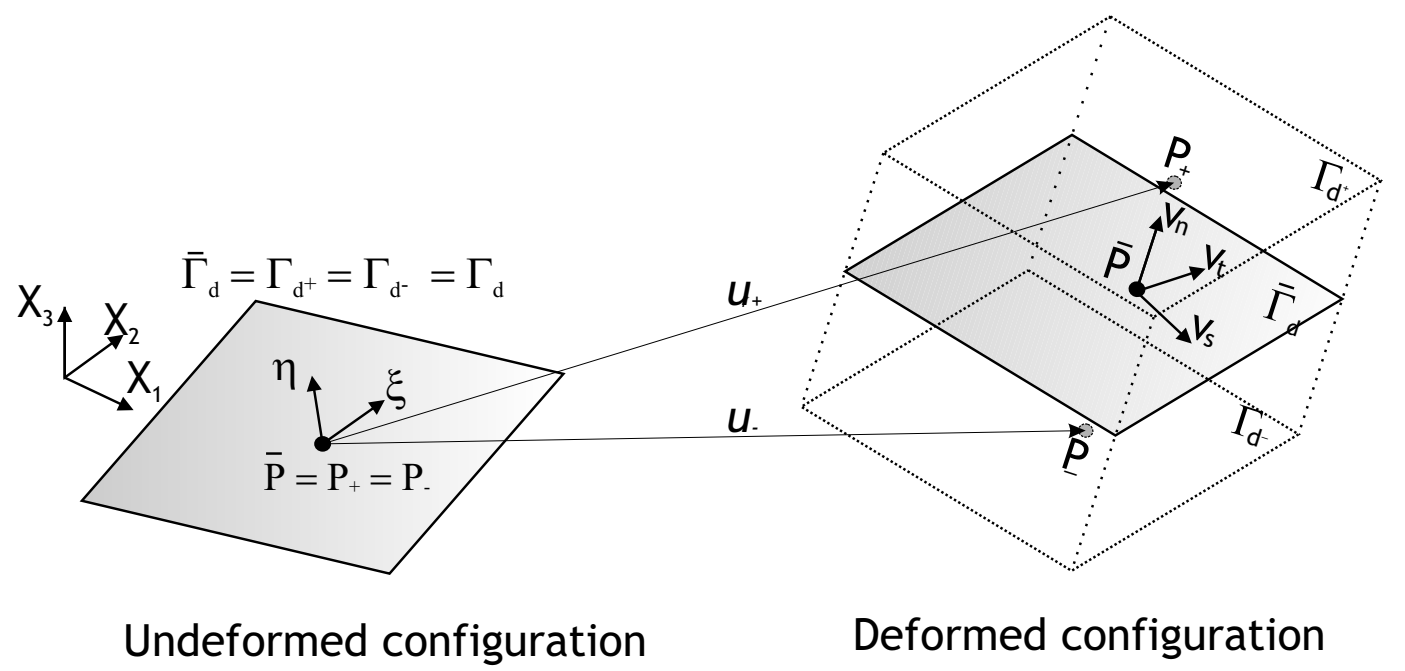

Fig. 3. Interfacial surface deformation. 


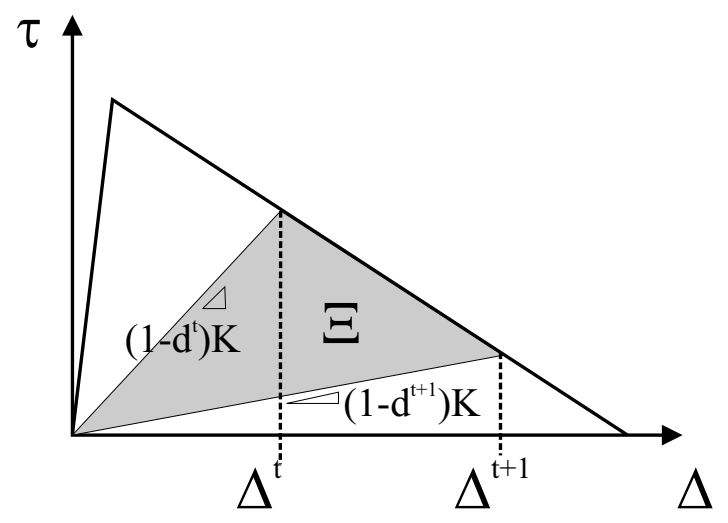

Fig. 4. Energy dissipation during damage evolution.

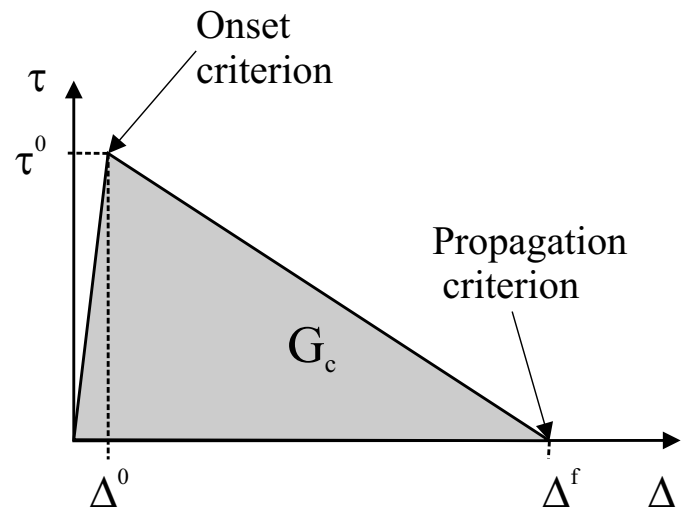

Fig. 5. A bilinear constitutive equation for the decohesion element for a mixed mode loading situation. 


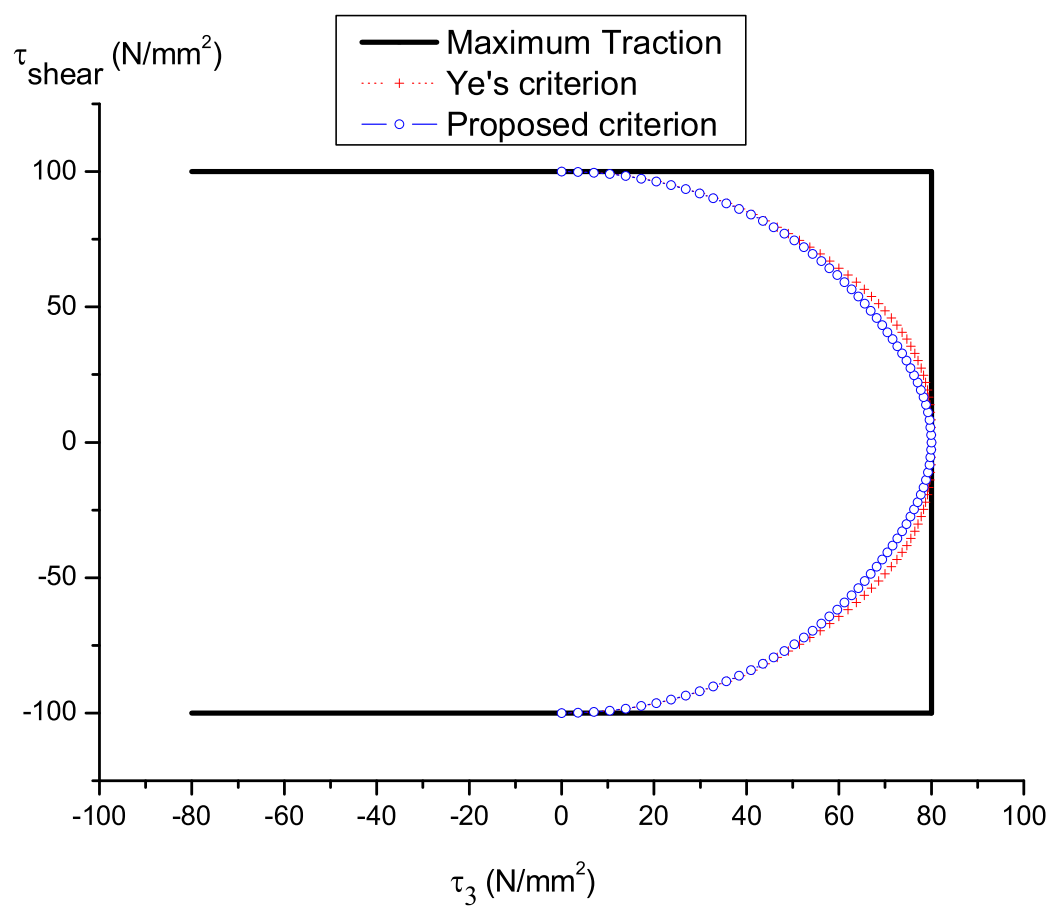

Fig. 6. Comparison between Ye's criterion, a maximum traction criterion and the new proposed criterion.

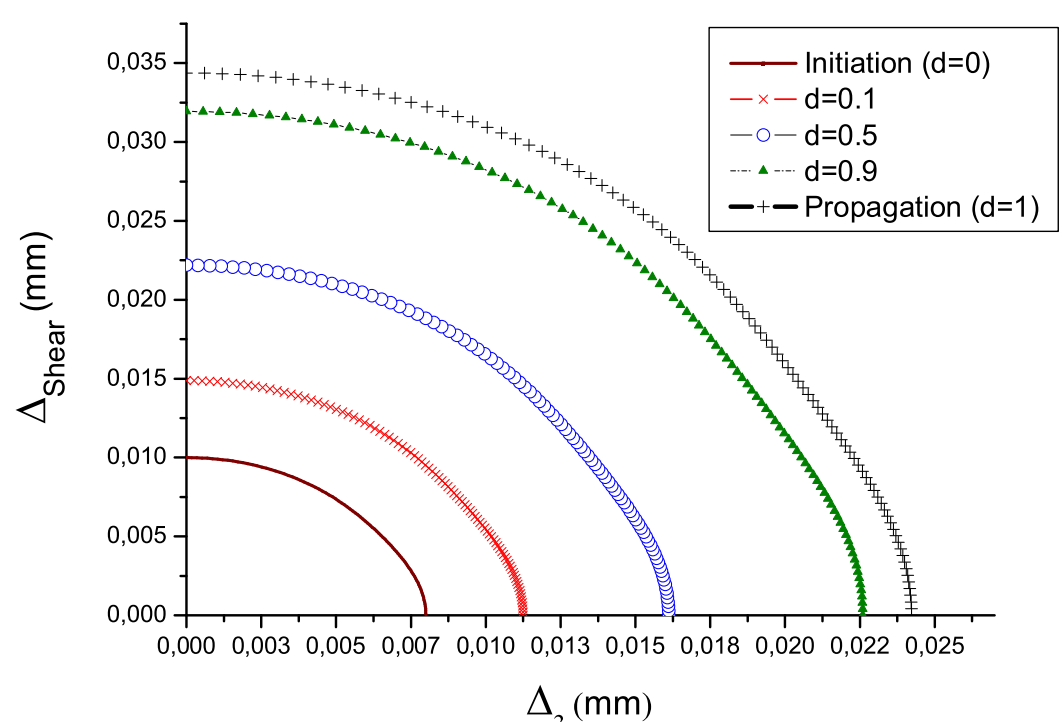

Fig. 7. Damage evolution surface in the relative displacements space. 


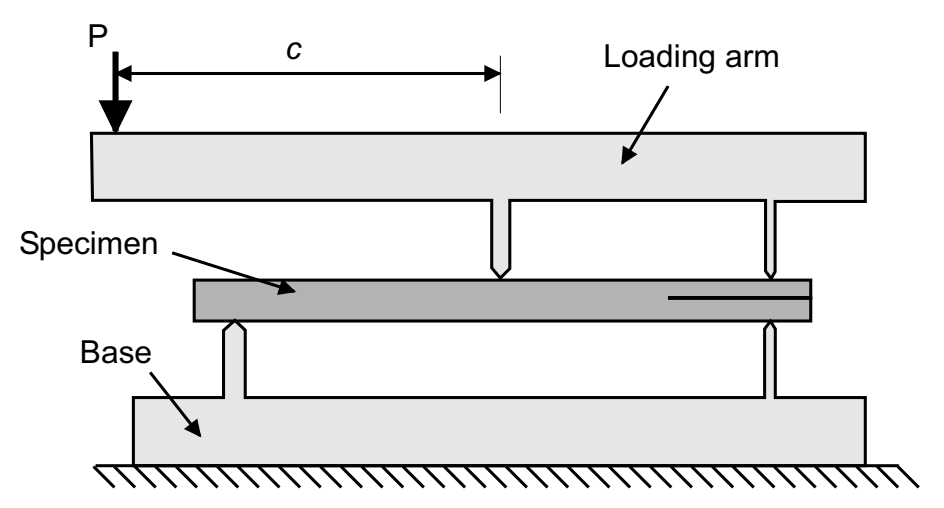

Fig. 8. MMB test specimen.

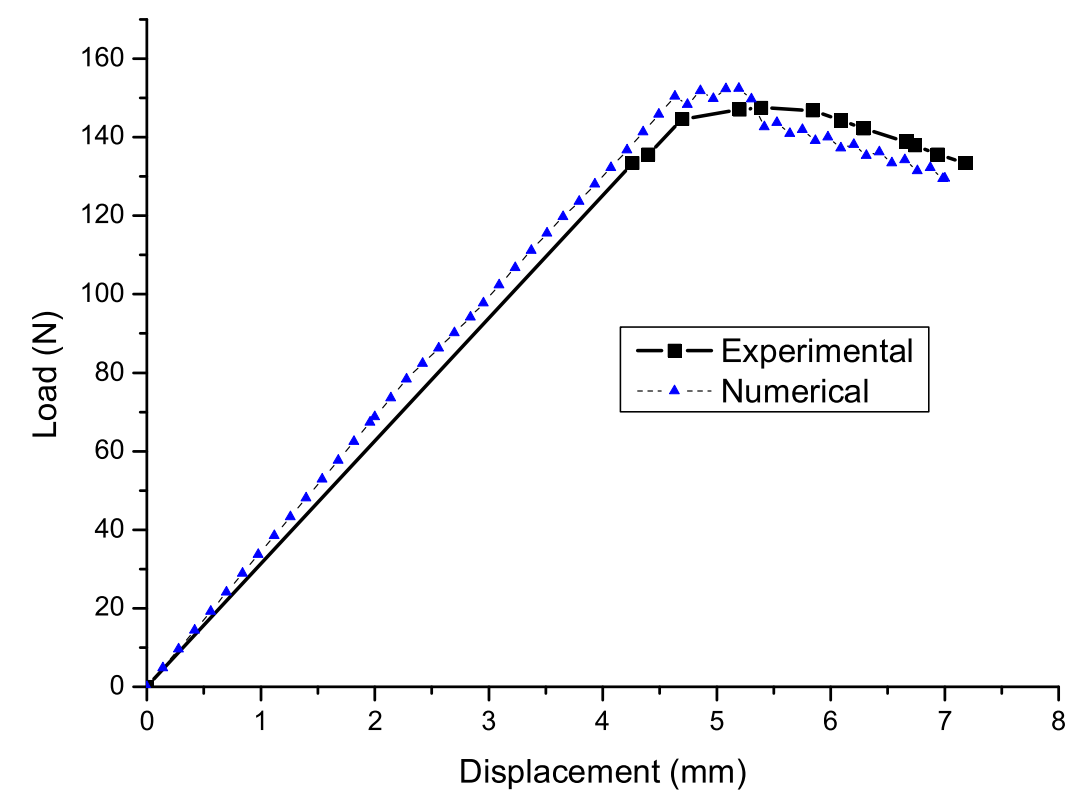

Fig. 9. Numerical and experimental results- pure mode I loading. 


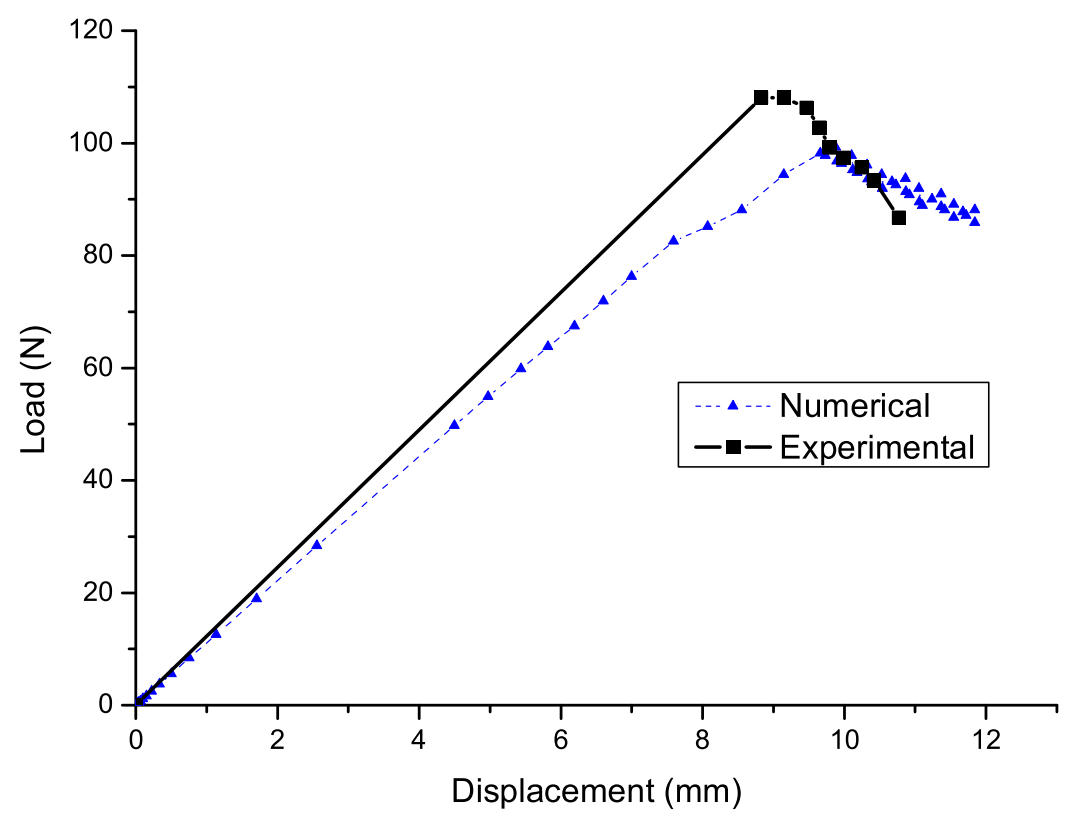

Fig. 10. Numerical and experimental results- mixed mode I and II loading with $\mathrm{G}_{I I} / \mathrm{G}_{T}=20 \%$. 


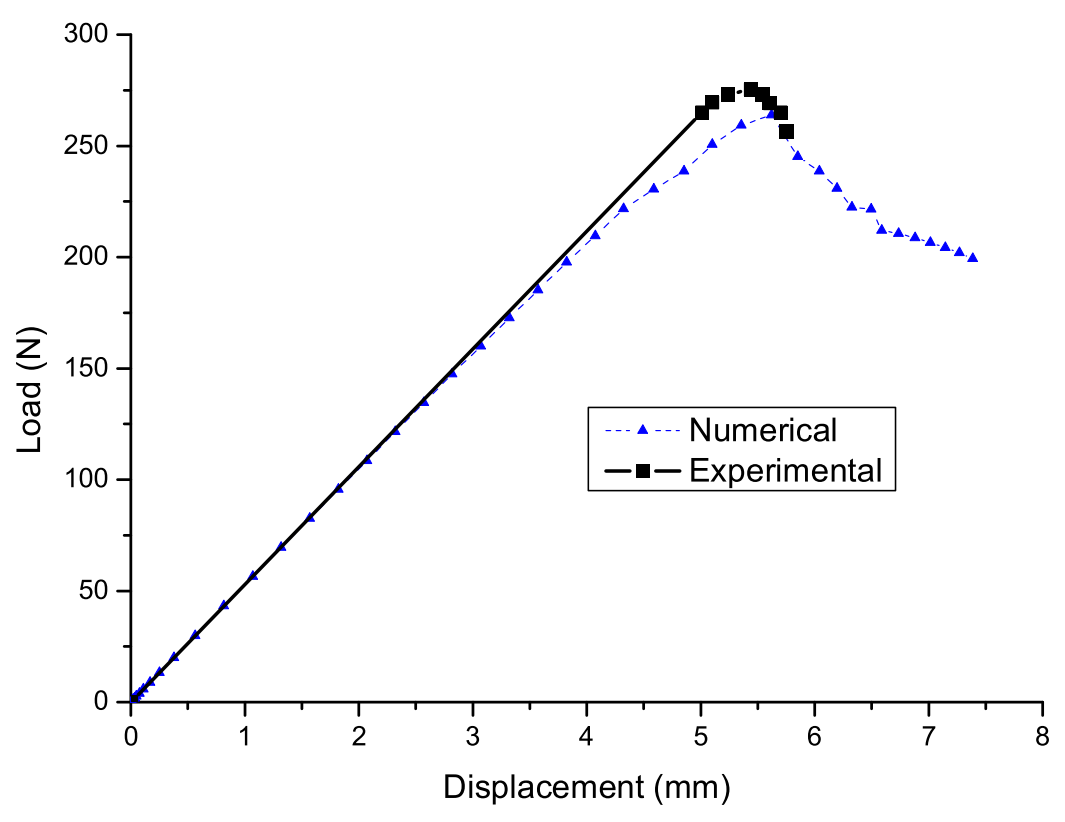

Fig. 11. Numerical and experimental results- mixed mode I and II loading with $\mathrm{G}_{I I} / \mathrm{G}_{T}=50 \%$. 


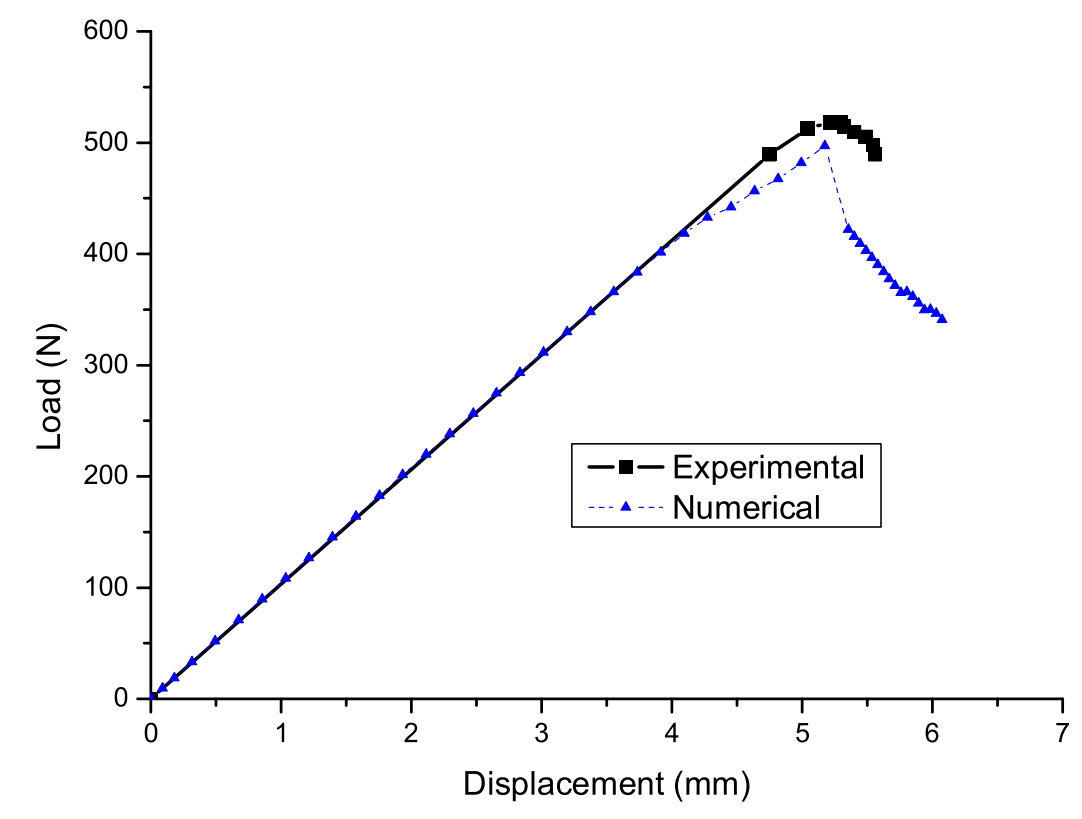

Fig. 12. Numerical and experimental results- mixed mode I and II loading with $\mathrm{G}_{I I} / \mathrm{G}_{T}=80 \%$.

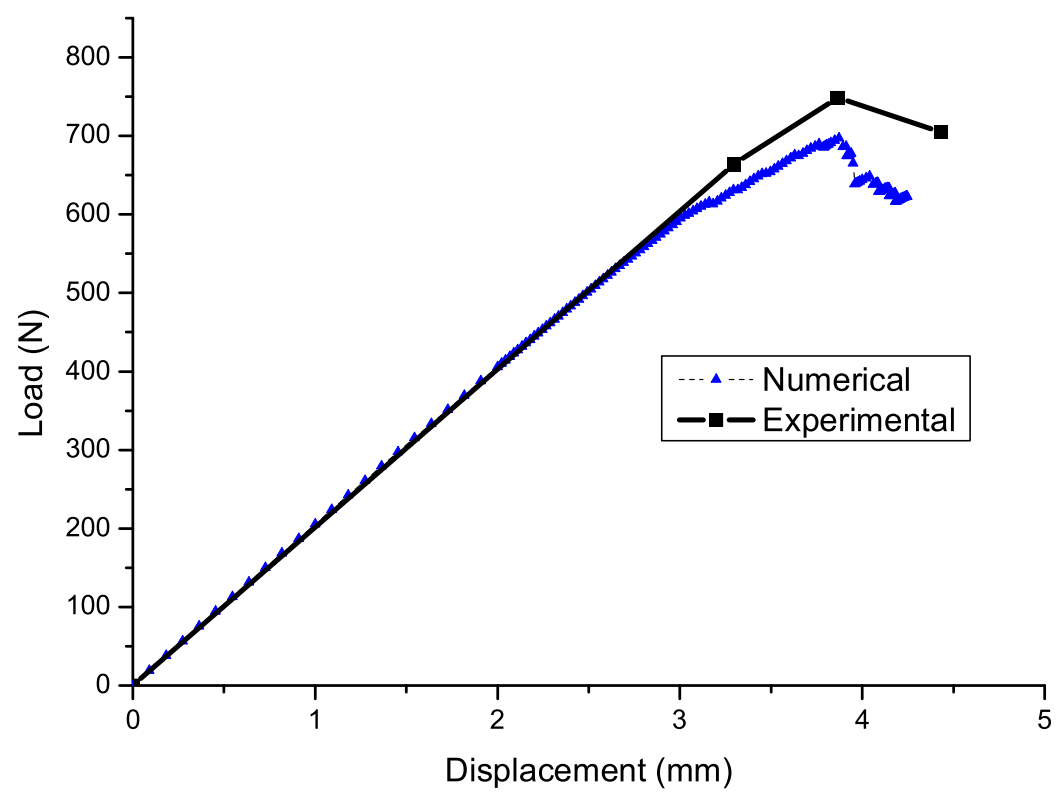

Fig. 13. Numerical and experimental results- pure mode II loading. 

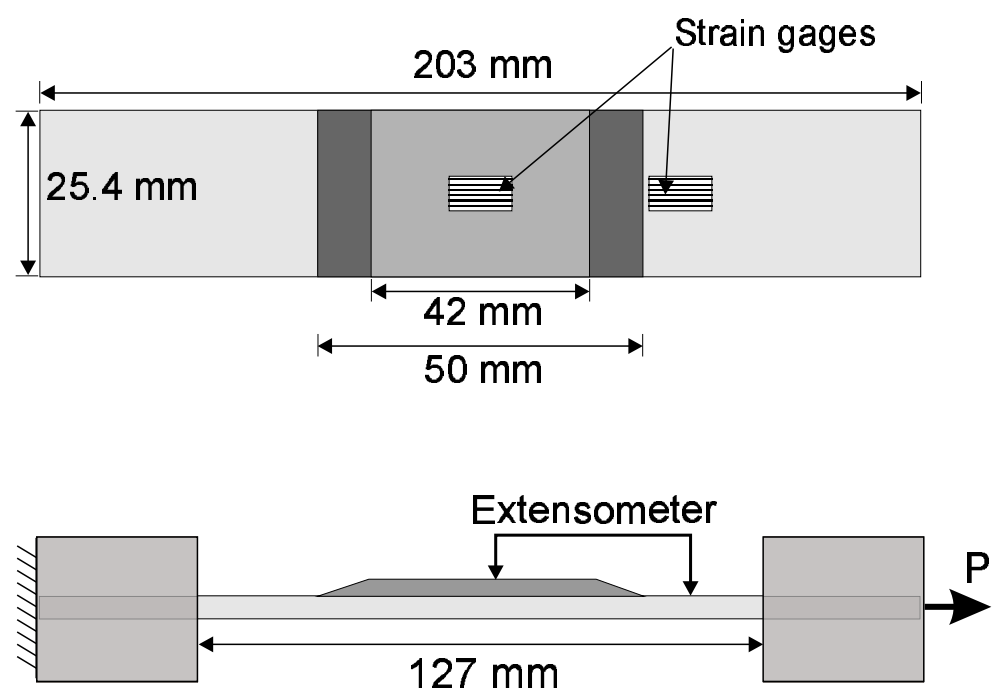

Fig. 14. Skin-stiffener test specimen.
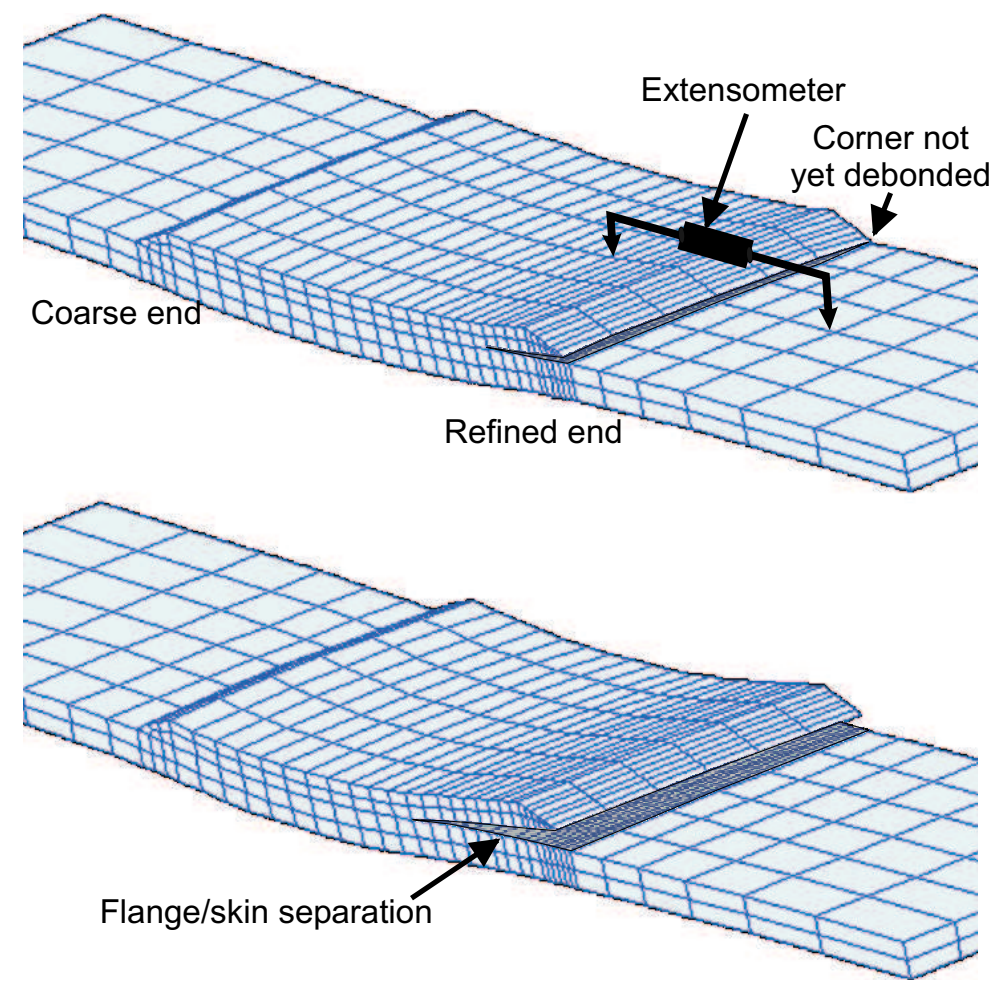

Fig. 15. Skin-Stiffener debonding. 


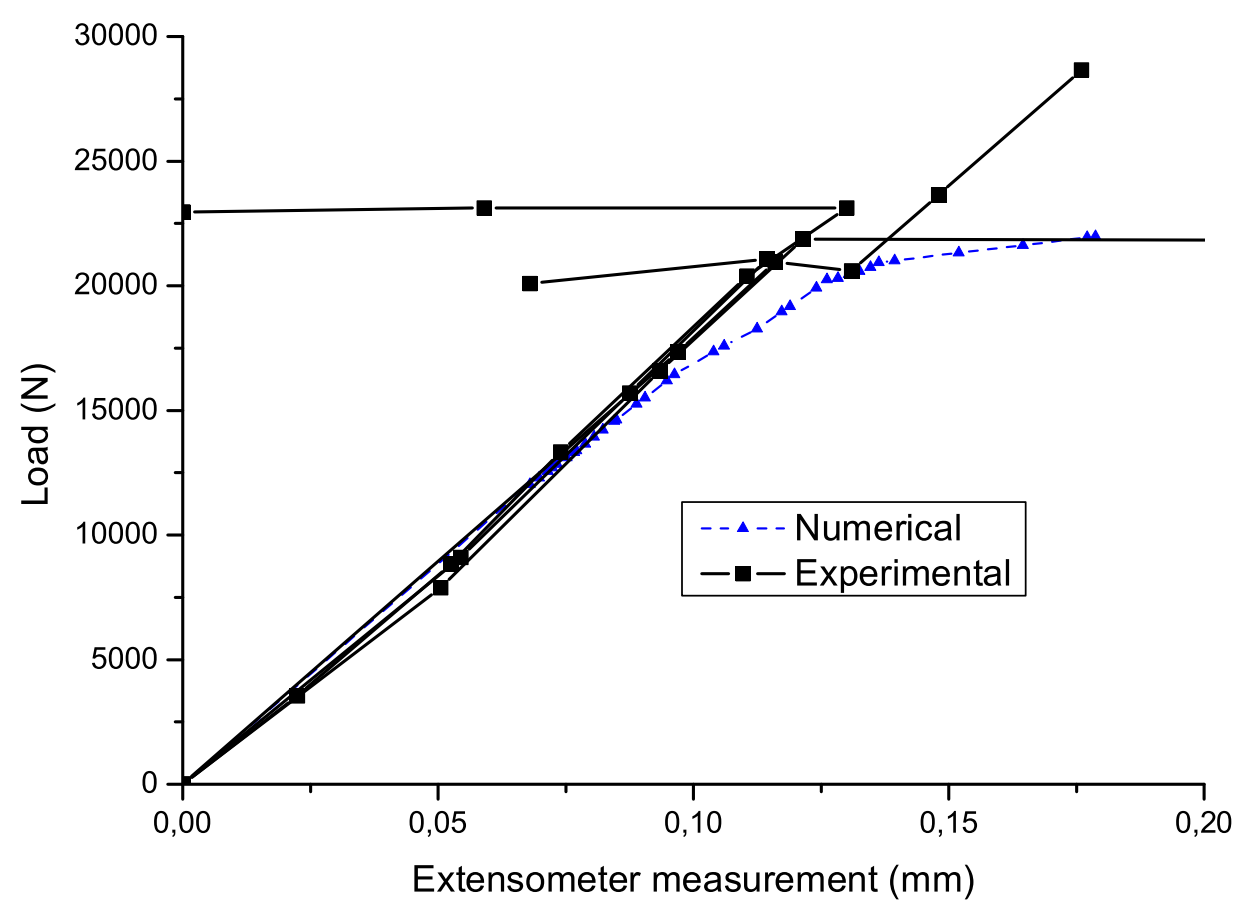

Fig. 16. Experimental and numerical load-extensometer displacement relations. 


\section{Tables}

Table 1

Ply properties.

\begin{tabular}{lllll}
\hline$E_{11}$ & $E_{22}=E_{33}$ & $G_{12}=G_{13}$ & $G_{23}$ & $\nu_{12}=\nu_{13}$ \\
\hline $122.7 \mathrm{GPa}$ & $10.1 \mathrm{GPa}$ & $5.5 \mathrm{GPa}$ & $3.7 \mathrm{GPa}$ & 0.25 \\
\hline \hline$\nu_{23}$ & $G_{I C}$ & $G_{I I C}$ & $\tau_{3}^{0}$ & $\tau_{2}^{0}=\tau_{1}^{0}$ \\
\hline 0.45 & $0.969 \mathrm{~kJ} / \mathrm{m}^{2}$ & $1.719 \mathrm{~kJ} / \mathrm{m}^{2}$ & $80 \mathrm{MPa}$ & $100 \mathrm{MPa}$ \\
\hline \hline
\end{tabular}

Table 2

Experimental data.

\begin{tabular}{llllll}
\hline \hline$G_{I I} / G_{T}$ & $0 \%(\mathrm{DCB})$ & $20 \%$ & $50 \%$ & $80 \%$ & $100 \%(\mathrm{ENF})$ \\
\hline$G_{C}\left[\mathrm{~kJ} / \mathrm{m}^{2}\right]$ & 0.969 & 1.103 & 1.131 & 1.376 & 1.719 \\
$a_{0}[\mathrm{~mm}]$ & 32.9 & 33.7 & 34.1 & 31.4 & 39.2 \\
\hline \hline
\end{tabular}


Table 3

Maximum loads.

\begin{tabular}{llll}
$G_{I I} / G_{T}$ & Predicted $[\mathrm{N}]$ & Experimental $[\mathrm{N}]$ & Error (\%) \\
\hline $0 \%(\mathrm{DCB})$ & 152.4 & 147.5 & 3.4 \\
$20 \%$ & 99.3 & 108.1 & -8.1 \\
$50 \%$ & 263.9 & 275.3 & -4.2 \\
$80 \%$ & 496.9 & 518.7 & -4.2 \\
$100 \%(\mathrm{ENF})$ & 697.1 & 748.4 & -6.9 \\
\hline \hline
\end{tabular}

Table 4

Material properties for IM6-3501-6 unidirectional graphite epoxy.

\begin{tabular}{llllll}
\hline \hline $\mathrm{E}_{1}(\mathrm{GPa})$ & $\mathrm{E}_{2}=\mathrm{E}_{3}(\mathrm{GPa})$ & $\nu_{12}=\nu_{13}$ & $\nu_{23}$ & $\mathrm{G}_{12}=\mathrm{G}_{13}(\mathrm{GPa})$ & $\mathrm{G}_{23}(\mathrm{GPa})$ \\
\hline 144.7 & 9.6 & 0.3 & 0.45 & 5.2 & 3.4 \\
\hline \hline
\end{tabular}


Table 5

Interface properties.

\begin{tabular}{lllll}
$\mathrm{G}_{I C}\left(\mathrm{Nmm}^{-1}\right)$ & $\mathrm{G}_{I I C}\left(\mathrm{Nmm}^{-1}\right)$ & $\mathrm{N}(\mathrm{MPa})$ & $\mathrm{S}(\mathrm{MPa})$ & $\eta$ \\
\hline 0.075 & 0.547 & 61 & 68 & 1.45 \\
\hline \hline
\end{tabular}

Table 6

Comparison between experimental and numerical results.

Experimental $(\mathrm{kN}) \quad$ Predicted $(\mathrm{kN}) \quad$ Error $(\%)$

Flange debond load 22.7

21.0

$-7.5$ 